\title{
EL VOCABULARIO JURÍDICO DE LOS AGRIMENSORES ROMANOS
}

\author{
Maria José Castillo Pascual ${ }^{*}$
}

\begin{abstract}
RESUMEN: El tema de este artículo es analizar algunos apectos de la terminología jurídica empleada por los agrimensores romanos en sus tratados. Hemos limitado el estudio a los vocablos de significado más problemático y que en la literatura gromática tienen una acepción específica, diferente, en ocasiones, a la babitual. Los términos en los que bemos centrado este estudio son los siguientes: 'abalienare/abalienatio', 'adsignatio', 'controversia', 'emere-vendere/ locare-conducere' $y$ 'munificentia'.

ZUSAMMENFASSUNG: In diesem Aufsatz werden einige juristische Begriffe, welche die römischen Feldmesser in ibren Schriften benutzen, behandelt. Dies ist bei einigen ausgewäblten, zentralen Begriffen durchgefübrt worden, deren Definition problematisch ist und deren Bedeutung zum Teil stark von der allgemein gültigen abweicht. Folgende termini werden an dieser Stelle bebandelt:'abalienare/abalienatio', 'adsignatio', 'controversia', 'emere-vendere/ locare-conducere'y 'munificentia'.
\end{abstract}

La figura del agrimensor romano nace con la colonización romana y alcanza su cima entre el tribundo de Tiberio Sempronio Graco (133 a. C.) y el reinado del emperador Adriano (117-138 d. C.), aunque sus ámbitos de actuación (militar y civil) y las tareas para las que eran requeridos en cada uno de ellos no estuvie-

* Profesora del Departamento de Ciencias Humanas y Sociales, Área de Historia Antigua, Universidad de La Rioja. 
ron claramente definidas desde un principio. En un primer momento, al ser Ia división del suelo un rito religioso y el catastro la imagen del Cosmos, eran los augures los que ejercían las funciones de agrimensores, pero después, y debido a la importancia que fue adquiriendo el proceso de colonización y municipalización, dentro y fuera de Italia, los IIIviri colonia deducendae agroque dividundo substituyeron a los augures, hasta que, finalmente, surgió la figura del finitor, el encargado de la divisio bajo las órdenes de los Xviri. Estos primeros agrimensores aún no estaban organizados en collegia ni se tenía en cuenta su preparación teórica y técnica; es bajo el Imperio cuando empiezan a aparecer las primeras corporaciones de agrimensores y nace la figura del mensor-funcionario.

Aunque ya en época imperial las funciones del agrimensor estaban claramente definidas, la frontera entre sus dos ámbitos de actuación, el militar y el civil, nunca fue del todo clara ni siquiera bajo el Imperio: con frecuencia encontramos a agrimensores militares en proyectos civiles, como es el caso de la centuriación del Africa Nova realizada bajo el reinado de Tiberio por la legio III Augusta ${ }^{1}$; o, por ejemplo, en la mayor parte de los testimonios que han llegado hasta nosotros sobre las disputas fronterizas en Dalmacia, fueron lo soldados quienes se encagaron de las operaciones técnicas (princeps posterior centurio, hastatus posterior centurio, centurio, praefectus castrorum $)^{2}$. La explicación no reside sólo en el objetivo que se escondía tras cada operación catastral, ni en las características particulares de la provincia, debemos también tener en cuenta dónde aprendieron los agrimensores los principios de su arte y fue dentro del ejército donde se formaron la mayor parte de los técnicos de la groma parentesco entre agrimensura y ejército es, a nuestro entender, lo que contribuyó en gran manera a que la separación entre ambas esferas nunca fuese claramente definida.

Las actividades desempeñadas por los agrimensores eran, por un lado, técnicas y, por otro, judiciales. Dentro de las primeras, la parcelación de la superficie de tierra a asignar era la más importante, en ella se comprendían todas las operaciones necesarias para orientar y trazar los ejes principales, para realizar mediciones salvando los obstáculos naturales, la colocación de los termini en las intersecciones, la realización de la forma, etc.; a ésta hay que añadir todas aquellas operaciones en las que la realización y el cálculo de mediciones eran imprescindibles: la tasación de propiedades en las operaciones de compra-venta, la restitución de los termini desaparecidos o trasladados de su posición original, la

1. Para LE BOHEC (1989, pp. 347 ss.) esta operación catastral fue más militar que política y más política que fiscal, por lo que es comprensible la intervención de dicha legión.

2. Para una recopilación de los termini que dan prueba de estos conflictos fronterizos, vid. WILKES 1974, pp. 258 ss.

3. A excepción, quizá, de los agrimensores de los tabularia imperiales, en su mayoría esclavos y libertos de origen griego, quienes se habrían formado en la Escuela de Alejandría y habrían contribuido a divulgar el manual y los métodos de Herón de Alejandría (HINRICHS 1974, p. 165). 
inspección de los confines, etc. Su principal actividad judicial era actuar como iudices, arbitri o advocati en las controversiae agrorum, para lo cual el agrimensor se debía comportar como un hombre prudente, bueno y justo, no dejarse llevar ni por la ambición ni por la vileza y, en todo momento, ser fiel a su creencia, a su disciplina y a las costumbres ${ }^{4}$. Por lo tanto, en la formación del agrimensor, y en relación con el aspecto técnico de su disciplina, era de gran importancia los conocimientos sobre geometría, astronomía, cosmología, etc; en sus funciones de juez, árbitro o abogado, debía conocer todo lo relacionado con las diferentes condiciones jurídicas del suelo, las leyes de las colonias y municipios, los edictos del emperador y de los gobernadores y, sobre todo, la doctrina jurídica de las controversia agrorum. Está claro que su formación técnica la recibió en el ejército, y en su formación jurídica, principalmente con respecto al último punto, los tratados de agrimensura de los primeros gromáticos desempeñaron un papel muy importantes.

Esa combinación de aspectos técnicos y jurídicos que caracterizaba la actividad del agrimensor y el contenido de los tratados de agrimensura es lo que nos ha llevado a tratar algunos de los términos jurídicos que en ellos se mencionan y que, en boca de especialistas de la groma y no del Derecho Romano, pueden resultar a veces un tanto confusos e imprecisos.

Los términos sobre los que vamos a centrar nuestra atención son aquellos que o bien son empleados por los agrimensores de forma inadecuada, o en un sentido poco frecuente o, por último, sus sinónimos no son del todo acertados; estos vocablos son los siguientes: abalienare/ abalienatio, absignatio, controversia, emere-vendere / locare-conducere y munificentia,

\section{ABALIENARE/ABALIENATIO}

Higino Gromático en su tratado Constitutio limitum dice que aquellos lugares públicos que son propiedad de la ciudad ( $u r b s$ ) no podían ni ser vendidos ni ser alienados del patrimonio público ${ }^{6}$, es decir, no estaba permitido transferir a otro legamente la propiedad sobre un parcela que pertenecía a los loca publica de la ciudad, pero esto tan sólo afectaba a los lugares públicos que estaban incluidos en la categoría de loca qui sunt in uso publico y que son a los que Higino Gromático se refiere en esta ocasión?.

4. AGENN. URB. (La. 90.3-9) = Th. 50.6-11: quamquam diversa sint et longe inter se discernere debeant, prudentiam tamen eandem / artifices babere debent et qui iudicaturi sunt et qui advocationes sunt praestituri. in iudicando autem mensor[em] bonum virum et iustum agere debet neque ulla ambitione aut sordibus moveri, servare opinionem et arti et moribus.

5. Sobre el nacimiento de los tratados de agrimensura en relación con la orientación jurídica de la misma, vid. CASTILLO (en prensa).

6. HYG. GROM. (La. 197.20-198.1) =Th. 160.22-161.2: Aeque territorio siquid erit adsignatum, id ad ipsam urbem pertinebit nec venire aut abalienari a publico licebit.

7. Sobre este aspecto, vid. CASTILLO (en prensa), cap. IV. 
Abalienare o abalienatio son sinónimos de alienare y alienatio respectivamente, por lo que el prefijo $a b$ - parece estar desprovisto de todo significado. Cicerón define de esta manera este término: Abalienatio est, eius rei quae mancipi est, aut traditio alteri nexu aut in iure cessio, inter quos ea iure civile fieri possunt t $^{8}$ la abalienatio es, a partir de este texto, la mancipatio entre aquellos que según el derecho civil podían ejercerla. Para DE VISSHER no es cierto que el prefijo $a b$ - esté carente de significado; según él, tal prefijo añade a alienare una idea de alejamiento, de abandono o de renuncia y esta idea está estrechamente relacionada con la naturaleza de las res mancipi, las cosas sometidas a la más antigua potestad romana llamada mancipium. La transferencia se explica así como una renuncia: el jefe de familia que adquiere la propiedad recibe un poder nuevo. Para él, abalienare es un término técnico ligado a las concepciones y formas más antiguas de la vida jurídica romana, término que en época clásica era raro y apenas empleado?.

El término se emplea siempre en relación con parcelas de tierra, edificios, esclavos y animales, es decir, en relación con las res mancipi. En la ley agraria del año 111 a. C. este vocablo se usa al referirse a los terrenos que se han convertido en propiedad privada por un acto de adsignatio y por la possesio de los antiguos posesores ${ }^{10}$. En las inscripciones funerarias se emplea este verbo para expresar la obligación que el difunto impone a sus herederos y descendientes de que la tumba no fuese transferida a otras manos ${ }^{11}$.

En los tratados de agrimensura tal término se refiere, al igual que en los ejemplos que hemos visto, a la mancipatio de parcelas de terreno y, quizá, con esta matiz de abandono o renuncia por parte del anterior titular de la propiedad que ha sido apuntado por DE VISSHCER ${ }^{12}$.

ADSIGNATIO (= ADSCRITIO, ADTRIBUTIO)

La adsigantio era la segunda fase del procedimiento administrativo por el cual una comunidad o un individuo recibía un lote de tierra; la primera operación era la divisio que consistía en la repartición geométrica del suelo y en la

8. CIC. Top. 5.28 .

9. DE VISSCHER 1936, pp. 133 ss.

10. LEX AGRARIA a. 111 a. C., 1.15 (FIRA I, n. 8): /(...)quod eius agri neque is abalielnavit abalienaueritue, neque beres eius abalienavit abalienav[eritque (...)]. En la lex Antonia de Termessibus (71 a. C.), una vez concedida la autonomía a los Termessi se les reconoce también el mismo derecho de propiedad sobre sus bienes, 11. 25-29 (FIRA I, n. 11): quei supra scriptei sunt, fuit, quod eius praeter / loca[ta] agros aedificia ipsei sua voluntate ab se non / abalienarunt, idem in eisdem rebus loceis agreis / aedificieis oppideis Termensium maiorum Pisidarum / ious esto.

11. Sobre ese aspecto, vid. DE RUGGIERO 1895, pp. 11 ss.

12. El mismo significado tiene en AGENN. URB. (La. 76.4-6) = Th. 35.13-14: (De modo controversia) si iam excessit memoria[m] abalienationis, solet iuris formula [non silenter] intervenire et inbibire mensores (...). 
delimitación física del lote, se trataba de una operación de carácter técnico mientras que la adsignatio era el propio procedimiento administrativo. No vamos a centrarnos aquí en las diferentes partes que componían él mismo, como eran la adscriptio o reclutamiento de los futuros colonos o la sortitio, el sorteo de los lotes para así lograr una distribución equitativa; sino en el significado jurídico de la asignacion, en sus consecuencias y en los términos sinónimos que emplean los agrimensores para referirse a la misma.

La adsignatio es, como ya hemos dicho al principio, un procedimiento administrativo; a través de él, se creaba una relación jurídica entre el suelo itálico o el provincial y una comunidad o un individuo ${ }^{13}$. Se aplica siempre en relación con la tierra pública propiedad del Estado romano y el vínculo que se establecía entre esta propiedad y la persona beneficiaria de tal asignación podía ser de varios tipos: propiedad privada optimo iure (romano o latino);possessio, aquí el Estado podía recuperar lo asignado; y la condicional o incondicional renuncia fiscal del Estado sobre el lote ${ }^{14}$.

Define, así mismo, en lenguaje gromático el ámbito jurisdiccional de las comunidades pues sólo lo asignado estaba bajo la jurisdicción de sus magistrados: "nada más que lo que a los veteranos haya sido dado o asignado pertenece a la jurisdicción de la colonia. Por consiguiente, no siempre todo lo que hubiera sido centuriado se suma a la colonia, sino sólo lo que hubiera sido dado o asignado" 15 .

Sinónimos de adsignare son en los tratados de agrimensura los verbos adscribere y adtribuere y, en numerosas ocasiones dare que siempre aparece junto a adsignare; por ejemplo, es habitual la expresión datus adsignatusque ${ }^{16}$ con la que se matiza juridicamente el significado tan amplio que tiene el verbo dare. Adscribere nada tiene que ver con la adscriptio de la que hemos hablado antes y a la que en ningún momento se refieren los agrimensores; adscribere o adscriptio es, en relación con el ager publicus $p$. $R$., un sinónimo de adsignatio ${ }^{17}$. Los términos adtribuere o adtributio no aluden, en este caso, ni a la institución pecunia adtributa, ni a civitas adtributa; se emplean en el sentido de ager o locus adtributus y con el mismo significado y consecuencias que la adsignatio; sin embargo, en un sentido estricto adtributio es la concesión de un terreno

13. FRONT. (La. 18.2-4) = Th. 7.5-7: (quae ad urbem pertinet) babet autem condicines duas, unam urbani soli, alteram agrestis, quod in tutelam rei fuerit adsignatum urbanae. AGENN. URB. (La. 80.8-9) = Th. 40.7-8: quorum propietas indubitae / ad eos pertinet, quibus est adsignata.

14. KUBITSCHEK 1894, c. 428.

15. HYG. (La. 120.1-5) = Th. 83.1-5: (...) nibil aliud ad coloniae iuris dictionem $<$ pertine >at quam quod veteranis datum adsignatumque sit. ita non semper quidquid centuriatum erit ad coloniam accedit, sed id tantum quod datum adsignatumque fuerit.

16. FRONT. (La. 21.4-6) = Th. 8.20-9.1: Nam et coloniarum aut municipiorum similis est condicio, quotiens loca, quae rei publicae data adsignata fuerint (...). Vid. LEX AGRARIA a. 111 a. C. (FIRA I, n. 8) 11. 76/ 77.

17. HYG. (La. 117.12-14) = Th. 80.14-16: Divisi et adsignati agri sunt qui veteranis alisue personis per centurias certo modo adscripto aut dati sunt aut redditi (...). 
(público o privado) sin que el que lo concede pierda los derechos de propiedad sobre el mismo, es decir, no es una adsignatio plena $^{18}$. Este último matiz es desconocido para los agrimensores ${ }^{19}$.

\section{CONTROVERSIA}

Con respecto al término "controversia", nos centraremos no sólo en el significado del mismo y en los sinónimos que, con mayor o menor acierto, emplean los agrimensores, sino también en algunos aspectos de la terminología y fraseología jurídica que nos encontramos en los tratados sobre las controversiae agrorum. Pero antes de tratar estos puntos, veamos primero cuáles son las controversias y por qué se originan.

Para Frontino el conjunto de las quince controversias (condiciones o genera controversiarum) que el distingue se puede dividir en dos categorias: las que están en relación con la frontera (finis) y las que se refieren a la superficie (locus) ${ }^{20}$. Agennio Urbico, por su parte, clasifica los diferentes genera controversiarum en status, es decir, según la naturaleza de los aspectos sobre los que las partes implicadas litigan o sobre los que se apoya el demandado ante el tribunal, y son los siguientes: status generalis (de carácter general), status anticipalis (preliminar), status initialis (inicial), status effectivi (en relación con las condiciones bajo las que una parcela es asignada), status iniectivi (en relación con parcelas de tierra u otro tipo de inmuebles que se encuentran ubicadas en un territorio de diferente categoría jurídica, o que es propiedad de otro o está dentro de la jurisdicción de otra comunidad) ${ }^{21}$.

Los genera controvesiarum son quince, pero no todos los agrimensores se centran en cada uno de ellos, a excepción de Frontino y Agennio Urbico. Higino, por ejemplo, es mucho más sintético y sólo se refiere a seis de ellos; los otros dos gromáticos, Sículo Flaco e Higino Gromático, ni tan siquiera los mencionan ${ }^{22}$.

I. La controversia "por la posición de los mojones fronterizos" (de positione terminorum controversia) tenía lugar cuando se pleiteaba por la incorrecta posición de los mojones que marcaban los límites entre propiedades. La labor del agrimensor aquí era observar las costumbres de la región con respecto a la colo-

18. DE RUGGIERO 1895a, p. 113.

19. FRONT. La. 18.8-9 = Th. 7.11-12:(...) quarum ex voluntate conditoris maxima pars finium coloniae est adtributa (...); SIC. FLA. (La. 161.15-16) = Th. 126.4-5: (...) ut saepe invenimus, uni foco territoria compluri[m]um acceptarum adtribuantur.

20. FRONT. (La. 9.2) $=$ Th. 4.2: Materiae controversiarum sunt duae, finis et locus.

21. AGENN. URB. (La. 63.23-26) =Th. 24.13-16: In omnibus his tamen agris superius nominatis quot genera controversiarum exerceantur, tractare incipiamus. nam et qualia sint et quot status babeant generales, diligenter intueri debemus.

22. Sobre las causas que quizá expliquen la falta de interés por la doctrina de las controversiae agrorum a partir de Higino, vid. CASTILLO (en prensa). 
cación y al tipo de mojones empleados; la trayectoria del rigor, línea imaginaria entre dos termini, y la actual posición del mojón o mojones por los que litigaban las partes. El conflicto concluía, en el caso de que así lo estimase el agrimensor, con la repositio de los termini que no estaban en su posición original ${ }^{23}$.

II. La controversia por el rigor (de rigore controversia) pertenece al mismo género que la controversia por el finis. Los agrimensores distinguen dos tipos de rigores: el del ager limitatus, marcado por la sucesión regular de termini que marcaban las intersecciones; y el del ager arcifinalis, marcado por la sucesión de todos aquellos elementos naturales que cumplían la función de termini. En el primer caso el pleito se resolvía con el restablecimiento de un limes ordinatus, gracias a la consulta de la forma; en el segundo, con una observación directa sobre el terreno ${ }^{24}$.

III. La controversia "por la frontera" (de fine controversia) es igual que la anterior. En ambos casos la línea divisoria entre propiedades vecinas tenía que tener una anchura de cinco o seis pies como rezaba en la lex Mamilia y siempre que esta franja de tierra fuese ocupada por uno de los dos vecinos con la intención de cultivar o de construir una obra, se originaba un pleito de estas características. La presencia del agrimensor era fundamental pues era el único que podía, gracias a sus conocimientos, dirimir el litigio; es la única controversia en la que tiene plenos poderes de decisión ${ }^{25}$.

IV. En el pleito "por el lugar" (de loco controversia) el afectado declaraba pertenecerle un lote determinado de tierra y exigía su devolución, para lo cual se basaba en el título de propiedad que daba prueba de los derechos que sobre ese terreno tenía ${ }^{26}$.

V. Una controversia "por la superficie o parcela" (de modo controversia) se desencadenaba cuando un propietario afirmaba no estar en posesión de la parcela que le correspondía según el plano catastral y, por lo tanto, reclamaba una revisión del mismo ${ }^{27}$.

VI. En la controversia "por la propiedad" (de proprietate controversia) se litigaba por a qué fundi o colonia correspondía la propiedad de una zona de pastos o bosques; estaba casi siempre en relación con zonas de pastos comunales. El juez o una de las partes implicadas podía reclamar los servicios de un agrimensor para que éste consultase la forma o el plano catastral y emitiese un juicio al respecto ${ }^{28}$.

23. FRONT. La. 10.1-11.2 = Th. 4.12-19; AGENN. URB. La. 70.17-72.4 $=$ Th. 30.12-31.1.

24. FRONT. La. $11.3-6=$ Th. 4.20-5.2; AGENN. URB. La. $72.5-21=$ Th. 31.11-26.

25. FRONT. La. $12 \cdot 1-7=$ Th. 5.3-9; AGENN. URB. La. 72.23-74.15 = Th. 31.28-33.11; HYG. La. 129. 12-131.9 = Th. 33.13-35.2.

26. FRONT. La. 13.1-6 = Th. 5.10-15; AGENN. URB. La. 74.16-75.26 = Th. 33.13-35.2; HYG. La. 129.12-131.9.

27. FRONT. La. 13.7-14.7 =Th. 5.16-6.2; AGENN. URB. La. 75.26-78.27 =Th. 35.3-38.25; HYG. La. 131.10-132.24.

28. FRONT. La. 15.1-16.2 = Th. 6.3-12; AGENN. URB. La. $78.28=$ Th. 39.1-40.16. 
VII. La controversia "por la posesión" (de possessione controversia) estaba dentro del ius ordinarium y se resolvía por la vía del interdictum possessorium $^{29}$. El origen de este pleito hay que buscarlo en la diferencia que marcaban los juristas romanos entre "propiedad" y "posesión": un propietario podía no ser el posesor y un posesor podía no ser el propietario; o bien, una misma persona era propietaria y posesora al mismo tiempo ${ }^{30}$.

VIII. La causa de la controversia "por el aluvión" (de alluvione controversia) eran los daños ocasionados por un río: a menudo, debido a la fuerza de 1 a corriente porciones de terreno de una orilla se depositaban en la otra o se formaba una isla en el centro del río. La cuestión aquí era averiguar a quién pertenecía lo así arrebatado y en esta investigación intervenía el agrimensor, siempre y cuando se le hubiese asignado al río algunas centurias o reconocido una determinada anchura, es decir, cuando su trazado y lo a él asignado apareciese reflejado en la forma o en el plano catastral ${ }^{31}$.

IX. Una controversia "por el derecho sobre el territorio" (de iure territorii controversia) tenía lugar cuando las tierras públicas, propiedad de la ciudad,

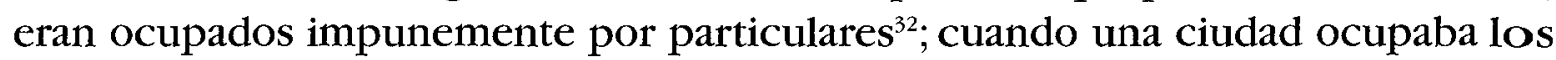
terrenos que otra ciudad tenía en el interior de su territorio aunque sin formar parte de él desde el punto de vista jurisdiccional ${ }^{33}$; los conflictos fronterizos entre dos o más comunidades también entraban dentro de esta categoría de controversia ${ }^{34} ; \mathrm{y}$, por último, el incumplimiento, generalmente por parte de los grandes propietarios, de las cargas municipales ${ }^{35}$.

X. El pleito por los subsiciva, la superficie de tierra que por no completar una centuria nunca se asignaba, se producía cuando algunos propietarios, aprovechando la vecindad de sus parcelas con los subsiciva, los ocupaban; su condición, en algunos casos, de loca vacantia facilitaba aún más la ocupación ${ }^{36}$.

XI. La controversia "por los lugares abandonados y excluidos" (de locis relictis et extraclusis) es del mismo tipo que la anterior ${ }^{37}$.

29. FRONT. La. $16.3-4=$ Th. 6.13-14; AGENN. URB. La. $80.20-81.2=$ Th. 40.17-23. ULP. Dig. 43.17.1.4: et ut Pedius ait, omnis de possessione controversia aut eo pertinet, ut, quod non possidemus, nobis restituatur, aut ad hoc, ut retinere nobis liceat quod possidemus (...).

30. ULP. Dig. 43.17.1.2: Huius autem interdicti proponendi cuasa baec fuit, quod separata esse debet possessio a proprietate: fieri etenim potest, ut alter possessor sit, dominus non sit, alter dominus quidem sit, possessor vero no sit:fieri potest, ut et possessor idem et dominus sit.

31. FRONT. La. 16.5-6 =Th. 6.15-16; AGENN. URB. La. 82.7-84.10 =Th. 42.3-44.23; HYG. La. 124.3$126.2=$ Th. $87.4-88.21$

32. FRONT. La. 17.1-19.5 = Th. 7.1-8.4.

33. AGENN. URB. La. $80.1-12=$ Th. 40.1-10.

34. AGENN. URB. La. 84.19-28 = Th. 45.6-15.

35. AGENN. URB. La. 84.29-85.15 = Th. 45.16-46.7.

36. FRONT. La. 20.3-6 =Th.8.7-11; AGENN. URB. La. 81.3-82.6 =Th. 40.24-42.2; HYG. La. 132.24$133.16=$ Th. $96.11-97.8$.

37. FRONT. La. $21 \cdot 7-22.8=$ Th. 9.3-12; AGENN. URB. La. $86 \cdot 26-87.8=$ Th. $47.9-22$. 
XII. La controversia "por los lugares públicos" está integrada dentro de la controversia por el derecho sobre el territorio y se entablaba siempre que los lugares públicos de la res publica, tanto los que estaban dentro del recinto urbano como fuera de él, eran ocupados por particulares de forma fraudulenta ${ }^{38}$.

XIII. Si se invadían y ocupaban ilegalmente las tierras adscritas a un templo o a un santuario se producía una controversia "por los lugares sagrados" (de locis sacris controversia); si lo era el suelo que entraba dentro de la categoría de religioso, es decir, el lugar donde estaba enterrado un cadáver, la controversia era "por los lugares religiosos" (de locis sacris religiosis controversia). La presencia del agrimensor en este conflicto se explicaba en tanto que la superficie que ocupaban estos lugares y su ubicación exacta estaba registrada en la forma ${ }^{39}$.

XIV. El pleito "por el paso o la contención del agua de la lluvia" (de aqua pluvia transitu o arcenda controversia) tenía lugar cuando alguien había realizado una obra para que el agua dejase de fluir de forma natural y tal construcción ocasionaba daños sobre una propiedad. La función del agrimensor se limitaba a restituir el finis en el caso de que éste hubiese sido dañado ${ }^{40}$.

XV. La controversia "por los caminos" (de itineribus controversia) se originaba cuando un propietario negaba el paso por los limites que siempre desempeñaban la función de caminos públicos ${ }^{41}$.

Por último, Frontino menciona la controversia "por los frutos de los árboles" (de arborum fructibus controversia) que tenía lugar cuando un propietario había plantado árboles frutales a lo largo de su finis y las ramas con los frutos estaban iclinadas hacia la propiedad del vecino. Este tipo de controversia, como dice el propio Frontino, ad solum non pertinet ${ }^{42}$.

En las controversias en las que predomina el aspecto técnico el agrimensor era reclamado para inspeccionar la forma o formae que se hubiesen confeccionado sobre estos territorios, con el fin de proceder a la restauración de los limites y de los confines; así ocurría en el caso de las controversias de positione terminorum, de rigore, de fine, de modo, de subsicivis y de locis relictis et extraclusis. En cambio, otras tenían un carácter exclusivamente jurídico y entonces se debía decidir si era necesaria o no la intervención de un agrimensor; ese es el caso de las controversias de loco, de proprietate, de possessione, de alluvione, de iure territorii, de locis publicis, de locis sacris et religiosis y de aqua pluvia arcenda. A esto se refieren Frontino y Agennio Urbico cuando utilizan las expresiones iure ordinario finiuntur (de locis sacris et religiosis controversia, de itineribus contro-

38. FRONT. La. 20.7-21.6 = Th. 8.12-9.2; AGENN. URB. La. 85.19-86.25 = Th. 46.11-47.8.

39. FRONT. La. 22.9-23.6 = Th. 9.13-20; AGENN. URB. La. 87.9-88.17 = Th. 47.23-48.25.

40. FRONT. La. 23.7-24.3 = Th. 9.21-10.4; AGENN. URB. La. 88.18-89.9=Th. 48.26-49.11.

41. FRONT. La. 24.4-12 = Th. 10.5-13; AGENN. URB. La. 89.10-24=Th. 49.12-25.

42. FRONT. La. $25 \cdot 1-26.2=$ Th. 10.14-18. 
versia en el caso del ager arcifinius $)^{43}$; ad ius ordinarium magis rescipti o ad ius ordinarium pertinebit o (de aquae pluviae transitu controversia) ${ }^{44}$; agitur plurimum iure ordinario, ius ordinarium moveri, plus potestatis babet izs ordinarium (de proprietate controversia) ${ }^{45}$; sibi vindicat ius ordinarium (de alluvione controversia $)^{46} ;\langle a>$ iure ordinario trabit (de iure territorii controversia $^{47} ;$ a iure ordinario accipiunt (de locis sacris et religiosis controversia) ${ }^{48}$, etc. Sin embargo, el ius ordinarium, es decir, la ley normal que se aplicaba en procedimientos regulares, no excluía la realización de medidas y por lo tanto la presencia del agrimensor ${ }^{49}$. El primero regulaba los procesos pero no negaba el carácter agrimensural que podían tener ciertos pleitos ${ }^{50}$. A este respecto Higino en su tratado sobre las controversias concluye con la siguiente frase, en relación con los pleitos por los caminos (via, actus, iter, ambitus, accessus), valles, fosas y fuentes: "todos estos partes no precisan nuestra labor sino la de una abogado de oficio, es decir, del derecho civil; realmente nosotros intervenimos entonces, cuando en las contorversias o algo (la linde) ha de ser alineado o si en la forma se encuentra anotado algo que ha de ser reinvindicado ${ }^{51}$.

Una vez expuesta a grandes rasgos la doctrina de las controversiae agrorum vamos a pasar a definir tal término, así como los otros nombres que tales pleitos reciben en los tratados de agrimensura.

Controversia se puede definir como querella, pleito, desavenencia, discusión o debate; es, en el aspecto que a nosotros nos interesa, una disputa legal entre particulares, pero también entre particulares y comunidades, como ocurre en el caso de la controversia por el derecho sobre el territorio o por los lugares públicos. Se trata, por lo tanto, de un pleito entre singulae personae; entendiendo aquí persona en un sentido jurídica: "persona jurídica" 52 , que es llevado ante un tribunal. Para KASER "controversia" es un término no técnico para designar al

43. FRONT. La. $22.10=$ Th. $9.14 ;$ La. $24.4-5=$ Th. $10.5-6$.

44. AGENN. URB. La. 88.19-20 = Th. 48.27-28; FRONT. La. 24.1-2 = Th. 10.1-2.

45. AGENN. URB. La. $79.3=$ Th. 39.4; La. $79.25-26=$ Th. 39.20-21; La. 80.13-14 $=$ Th. $40.11-12$.

46. AGENN. URB. La. $82.9=$ Th. 42.5 .

47. AGENN. URB. La. $84.14=$ Th. 45.1

48. AGENN. URB. La. 87.11-12 = Th. 47.25.

49. En algunas controversias, como las que tenían lugar por la ocupación de los lugares públicos o los conflictos fronterizos entre dos o más comunidades, era habitual la intervención del emperador, de un legado especial o del gobernador de la provincia, lo cual nos hace plantearnos el hecho de que se tratase de una cognitio extra ordinem, ya que el juez privado desaparece y su lugar es ocupado por un funcionario que ha sido delegado por el emperador o por un alto magistrado como el gobernador de la provincia.

50. BRUGI 1897, p. 202 ss.

51. HYG. (La. 134.9-13) =Th.98.2-5: quae omnes partes non nostra $<m>$ sed forensis officci, id es $<t>$ iuris civilis, operam exigunt: nos vero tunc eis intervenimus, cum aut derigendum aliquid est quaestionibus aut, si forma aliqua aliquid notatum invenitur, repetendum est.

52. Sobre el concepto de persona aplicado a colectivos y municipalidades, vid. ELIACHEVITCH 1942. 
"Zivilprozeß”, el procedimiento legal que se dividía en dos partes: el proceso de decisión en el que se decidía sobre el tema de tal controversia en un juicio y la ejecución de sentencia ${ }^{53}$. La definición como disputa legal la encontramos también en LEIST, para quien el término debe aplicarse principalmente a las disputas dentro del derecho privado y no a las que estaban dentro del derecho penal; para él, además, esta denominación se ajusta más a la disputa legal que aún no se ha convertido a través de la contestatio en una auténtico pleito ${ }^{54}$. En relación con la docuentación epigráfica, el término se emplea para referise a los conflictos territoriales que tenían lugar entre estados y comunidades y que se resolvían mediante árbitros ${ }^{55}$.

Los gromáticos también emplean para referirse a controversia los términos contentio, disputatio, lis, querella y quaestio. El primero, contentio, es, al igual que controversia, una disputa llevada a juicio y en este sentido lo utiliza Agennio Urbico cuando en el pleito por los lugares sagrados y religiosos dice que "frecuentemente entre comunidades tiene lugar por estos lugares una contentio de este tipo" "56; Higino lo emplea en relación con las controversias, en este caso contentiones, que se originaban por la vías, caminos, accesos, etc. ${ }^{57}$. Disputatio no se aleja en su significado del anterior y viene a significar lo mismo que controverisa, disceptatio y contentio; sin embargo, su acepción más usual es la de escrito jurídico en el que se contienen casos discutidos por los juristas en sus funciones de maestros $^{58}$ y en este sentido se trataría más de una discusión o debate que de una disputa legal ${ }^{59}$. Frontino emplea el término cuando explica cómo nace una controversia por los frutos de los árboles, en este caso inter adfines movent disputationem $^{60}$.

El siguiente término es lis que es un sinónimo de litigium $^{61}$. Con el se hace referencia tanto al juicio o pleito como a lo que es objeto del mismo ${ }^{62}$. Es por lo tanto una disputa ante un tribunal que también se suele designar como actio, controversia, quaestio o contentio; en el lenguaje común significa debate o querella. Según Isidoro y a partir de Virgilio, lis tomó el nombre de la controversia

53. KASER 1966, p. 1.

54. LEIST 1900, c. 1164.

55. DE RUGGIERO 1910, p. 1188.

56. AGENN. URB. (La. 87.24-26) $=$ Th. 48.13: Sed et inter res publicas frequenter eius modi contentio agitatur de bis locis (...).

57. HYG. (La. 134.7-9) =Th. 97.23-98.1: De via e<t> actu et itinere et ambitu et accessu et rivis et vallibus fossis fontibus saepe moventur contentiones. Con la misma acepción, vid. GAIUS, Inst. IV.166 (contentio fructus).

58. BERGER 1953, p. 439.

59. GAIUS, Inst. I.188: Ex his apparet, quot sint species tutelarum. si vero quaeramus, in quot genera bae species diducantur, longa erit disputatio (...); vid. IUL. Dig. 50.17.65.

60. FRONT. La. $26.2=$ Th. 10.18 .

61. El vocablo lis pertenece a la fase más antigua de la lengua latina y en origen se encontraba bajo la forma stlis, prueba de ello son los Xviri stlitibus iudicandis, vid. FEST. s.v. "Stlatta", P. 455.

62. VARR. L.l. 7.93: (...) itaque quibus res erat in controversia, ea vocabatur lis (...). 
(contentio) por los limites $^{63}$. Una vez que se hubo instituido el ordo iudiciorzm privatorum, lis hacía referencia a las declaraciones (contestationes) de las partes ante un magistrado, esto era lo que posteriormente llevaba a una litis contestatio y después a la sentencia del juez. En los documentos que no tienen un carácter oficial lis tiene un significado muy genérico, el de controversia o causa y en los oficiales designa, ya en época clásica, a todo tipo de actiones $^{64}$.

En dos de las ocasiones en las que los agrimensores emplean este vocablo, podemos apreciar la sutil diferencia que dentro del Derecho Romano existe entre lis y controversia. Al tratar sobre el pleito por la linde, Agennio Urbico emplea en dos ocasiones la construcción controversia ad litem deducere, con la que quiere expresar que la controversia acabará en una disputa legal ${ }^{65}$; en la controversia por la posición de los mojones fronterizos, Agennio Urbico dice que se trata de una disputa de tipo preliminar y "casi amenazadora de alguna lis" ${ }^{\prime 6}$. Esta expresión es similar a la expresión técnica rem in iudicium deducere y da prueba de que la controversia no es el proceso en sí, el cual sólo se continua con el acuerdo entre ambas partes y la autorización del magistrado en la litis contestatio, si no la exposición de la demanda por una de las partes y de ahí que sea habitual en relación con esta fase, que podríamos definir como "fase preparatoria del

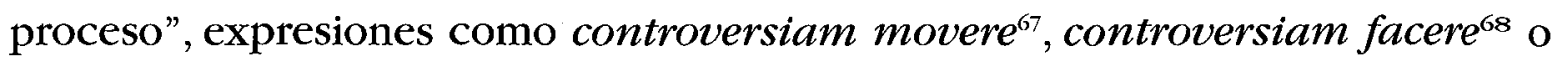
controversiam inferre ${ }^{69}$ que nos indican en sentido estricto la fase in iure del procedimiento antes de la litis contestatio ${ }^{70}$. Podemos concluir de lo anterior-

63. ISID. Orig. 18.15.4: Lis a contentione limitis prius nomen sumpsit. De qua Vergilius (Aen. 12.898); VIRG. Aen. 12.898: limes agro positus, litem ut discerneret arvis.

64. Lis aparece en las fuentes literarias vinculado a iurgium (CIC. Leg. 1.21, si jurgant en relación con la controversia por la frontera), sin embargo este segundo no es un término técnico para un proceso arbitral. Iurgium hace referencia a la disputa entre vecinos (de ahí el empleo que hace Cicerón del verbo) o entre parientes que se lleva ante un magistrado (Papiniano habla de iurgium para referirse a un debate entre hermanos, Dig. 10.2.57). Con el tiempo la palabara iurgium perdió esta matización y adquirió el sentido general de proceso; en $C J 6.2 .22 .4$, es un desacuerdo entre juristas.

65. AGENN. URB. (La. 67.16-19) = Th. 27.28-28.2: <Falsa pro>positio est, cum controversia alium habeat statum generalem et alio litem deducatur. vera propositio est cum per stat<um> generalem controversia[m] ad litem deducitur.

66. AGENN. URB. (La. 72.2-3) = Th. 31.8-10: (de positione terminorum controversia) est enim anticipalis et quasi comminatio quaedam litium (...).

67. ULP. Dig. 1.7.25.pr.: Post mortem filiae suae, quae ut mater familias quasi iure emancipata vixerat et testamento scriptis beredibus decessit, adversus factum suum, quasi non iure eam nec praesentibus testibus emancipasset, pater movere controversiam probibetur.

68. ULP. Dig. 50.10.5.pr.: (...) 'si vero dies datus est, pecuniam deponant intra diem, si aut non invenire se statuas dixerint' aut loco controversiam fecerint: semisses protinus pendant'.

69. PAUL. Dig. 35.3.4.pr.: Haec autem satisdatio locum habet, si iusta causa esse videbitur: nam iniquum erat omnimodo caveri nondum illata controversia litis, cum possint ei lusoriae minae fieri $(. .$.$) .$

70. GAIUS, Inst. IV.139: Certis igitur ex causis praetor aut proconsul principaliter auctoritatem suam finiendis controversiis interponit. Como se puede deducir del texto, Gayo no hace distinción entre la presentación de la demanda y el proceso en sí, debido, quizá a que el magistrado (un pretor o un procónsul) concluyen con la controversia desde un primer momento impidiendo así que se lleve a cabo el lis, o mejor dicho, la litis contestatio que se pretendía. 
mente dicho que lis y controversia no son en un sentido estricto términos sinónimos, sino dos partes diferentes de una disputa legal.

Querella y quaestio son los dos últimos vocablos que aparecen en los tratados de agrimensura como sinónimos de controversia. El primer término lo utiliza Agennio Urbico en relación con la controversia por la contención del agua de la lluvia y tiene el sentido vago de asunto judicial, nada tiene que ver con las categorias de querellae que se distinguen dentro del Derecho Romano ${ }^{71}$. El segundo, quaestio, es en su forma singular un tipo de procedimiento criminal y, en su forma plural, un tipo de escrito jurídico en el que se recogían los casos, ficticios o no, discutidos por los juristas; en un sentido amplio es una investigación judicial y también el sujeto de discusión o de disputa. En el caso que aquí nos ocupa, es una disputa o controversia entre vecinos, disputas causadas por el aluvión, conflictos en torno a los subsiciva, pleitos fronterizos entre comunidades, etc. ${ }^{72}$.

Todos ellos, excepto el de $l i s$, son empleados por los agrimensores en su acepción de disputa o pleito, o sea, de controversia tal y como la hemos definido. Son sinónimos que se han adoptado por la necesidad de una variación lexical pero sin la intención de introducir matizaciones o de hacer referencia a otras instituciones procesales.

En último lugar nos referiremos a los verbos que aparecen asociados con la palabra controversia o con sus sinónimas. El verbo finere supone, según CASAVOLA, atribuir a la controversia el valor subjetivo de "demanda de un proceso" sobre una determinada cuestión y no el objetivo del proceso y jamás de disputa material ajena, por completo, al proceso $^{73}$; los agrimensores utilizan la expresión controversia finere en aquellas que tenían un carácter principalmente jurídico y que "se concluían dentro del derecho ordinario"74. Movere es el más habitual, no sólo dentro de los tratados de agrimensura sino también en de la literatura jurídica ${ }^{75}$ y significa iniciar o comezar, haciendo más hincapié, principal-

71. Sobre la naturaleza de las querellae y sus funciones en relación con las formas del procedimiento, vid. COLLINET 1953, pp. 251 ss..

72. HYG. Th. 74.24-25: $<<$ Quotiens quid inter vicinos extiteri[n]t quaestionis, ab agrimenso$r i<b u>s$ prompt $<i>u s$ boc quaerendum.; Th. 75.4-5: eadem quasi magistra sit eorum, quae [est] in quaestione[m] sunt (...);(La. 125.16-18) $=$ Th. 88.16-18: in qua regione si de alluvione age[re]tur, magnae quaestiones erunt, ut secundum <a>es quidquid venditum est restituatur emptori; (La. 132.24-25) $=$ Th. 96.11-12: De iure subsicivorum subinde quaestiones moventur; Src. FL. (La. 163.25-27) $=$ Th. 128.13-15: de quibus, id est territoriis, si quando quaestio movetur, respiciuntur leges civi<tati $>$ bus datae (...); etc.

73. CASAVOLA 1959, p. 736.

74. Así lo vemos, por ejemplo, en Frontino, (La. 22.9-10) = Th. 9.13-14: De locis sacris et religiosis/ controversiae plurimae nascuntur, quae iure ordinario finiuntur (...); (La. 24.4-5) = Th. 10.56: De itineribus controversia est quae in arcifiniis agris iure ordinario finitur (...).

75. Sobre esta cuestión, vid. ALBERTARIO 1914, pp. 305 ss., donde el autor presenta y analiza los textos en los que se ha adoptado la expresión controversiam movere. AGENN. URB. (La. 63.10$12)=$ Th. 23.22-24.1: nam et controversias / inter se tales movent, quales in agris inmunibus et privatis solent evenire. 
MARÍA JOSÉ CASTILLO PASCUAL

mente, a esa primera fase de la disputa legal a la que nos hemos referido anteriormente. Agere es sinónimo del verbo anterior y es utilizado frecuentemente por Agennio Urbico ${ }^{76}$; exercere o fieri o nasci son los otros verbos que reflejan el surgimiento de una disputa entre dos o más partes por cuestiones relacionadas con el locus o con el finis. Todos estos verbos son los que utilizan los agrimensores para explicar por qué tenía lugar una u otra controversia, limitándose exclusivamente a los aspectos técnicos de las mismas en dos puntos: el trazado de la frontera y la determianción de la titularidad del derecho de propiedad sobre una parcela determinada. En ningún momento encontramos en la doctrina gromática de las controversias un enfoque desde el punto de vista del derecho procesal, ni ninguna identificación de éstas con las actiones o con otros instrumentos judiciales; sólo las cuestiones técnicas son el centro del discurso.

\section{IUDEX/ARBITER}

El agrimensor, como ya hemos señalado en un principio, podía desempeñar dentro de las controversiae agrorum las funciones de juez, árbitro o abogado; él era quien juzgaba cuándo las cuestiones técnicas de su disciplina eran fundamentales para resolver la disputa ${ }^{77}$. Pero esta labor no era realizada por todos los agrimensores, sino sólo por la categoría superior de agrimensores, aquellos que pertenecían al ordo equester, viri egregii, y que eran designados como auctores, professores y togati augustorum ${ }^{78}$.

La resolución de muchas de las controversias exigía conocimientos técnicos y profesionales muy concretos, es por eso que es más correcto, desde el punto de vista jurídico, designar a los agrimensores que decidían sobre las mismas como árbitros y no como jueces; pero ambos términos se utilizan indistintamente, a este respecto no tenemos más que fijarnos en las inscripciones colocadas tras una disputa fronteriza, solucionadas por un arbiter datus, un arbiter ex compromisso, un iudex datus o un iudex ex compromisso ${ }^{79}$.

Los iudices, por el contrario, decidian sobre disputas legales en las que se enfrentaban dos partes con afirmaciones contradictorias, dando la razón a una de ellas; para su decisión debían seguir fielmente las normas de derecho, por lo que en en su actuación no se podían mover con libertad. Por otra parte, tampoco pre-

76. AGENN. URB. (La. 81.9-10) = Th. 41.3-4: (De subsicivis controversia)de quo maximae controversiae agitantur.

77. Sobre estas funciones y cómo se debía comportar, vid. AGENN. URB. La. 90.1-21 = Th. 50.351.3 .

78. AGENN. URB. (La. 90.13-14) = Th. 50.14-15: (...) totum autem boc iudicandi officium et bominem et artificem exigit egre/gium.

79. Para algunos ejemplos de estas disputas bien entre comunidades o bien entre particulares y comunidades derimidas por un iudex o arbiter datus o ex compromisso, vid. DE RUGGIERO 1895b, pp. 613 ss.; CASTILLO (en prensa), cap.VI: De iure territorii controversia. 
cisaban, a diferencia de los árbitros, de conocimientos técnicos: no debían evaluar el conflicto o resolver una situación caótica y confusa entre las partes haciendo de mediadores, teniendo en cuenta todo tipo de observaciones y aplicando sus conocimientos técnicos, como el árbitro, sino tan sólo juzgar a favor de un o de otro. Eran nombrados para cada proceso por un magistrado de entre la lista de aquellos que podían ejercer tal función (album iudicum); sin embargo, los árbitros además de poder ser nombrados por el magistrado podían serlo por las partes en litigio. Aunque la diferencia entre ambos es clara, frecuentemente el iudex toma el nombre de arbiter, un ejemplo de esta doble denominación tenemos en la ley de las XII Tablas ${ }^{80}$; en las leyes republicanas ambos aparecen juntos ${ }^{81}$ y en época de los juristas clásicos hay un uso indistinto de uno u otro término. Esta oposición entre iudex y arbiter se equilibró tempranamente.

Aunque la distinción entre juez y árbitro pronto desapareció y ambos términos se usaron indistintamente, todas aquellas controversias que exigían de conocimientos técnicos eran sentenciadas por un árbitro, e independientemente de que éste aparezca designado como iudex, se trata de un arbitrium y no de un iudicium, así es como se deben entender todas las controversias por cuestiones de fronteras, como arbitrajes ${ }^{82}$.

\section{EMERE-VENDERE / LOCARE-CONDUCERE}

En relación con el ager vectigalis, la tierra pública propiedad del Estado o de una ciudad que era alquilada a particulares a cambio del pago de un vectigal ${ }^{83}$, Higino no hace ninguna distinción, al tratar sobre el tipo de concesión de la que era objeto, entre emere, vendere, locare y conducere, pues utiliza indistintamente unos y otros: “(...) unos por cinco años, pero otros por mancipes son comprados, es decir, alquilados por cien años; pero muchos, terminado aquel periodo, por seguda vez los venden y los alquilan pues así es costumbre en los agri vectigales"; los mismo nos encontramos más adelante:"En cambio, los mancipes, los que compraron por la ley llamada derecho del vectigal, alquilaron o vendieron por centurias a cada uno de los posesores" ${ }^{84}$. El empleo indistinto de

80. LEX XII TAB. (FIRA I, caput I) 2.2: quid borum fuit [vitium] iudici arbitrove reove, eo dies diffusus esto; vid. 9.3 .

81. FRAG. ATESTI. (FIRA I, n. 20) 1. 15: (..) quod privatim ambigetur, iuris dictil]/o iudicis arbitri recuperatorum datio (...).

82. Sobre el arbitraje y las dos categorías que se reconocen en el Derecho romano, vid. DE RUGGIERO $1895 \mathrm{~b}$, pp. 613 ss.

83. Vectigal es el término con el que se designa cualquier tipo de ingreso público, principalmente los procedentes de bosques, pastos, minas, salinas, ríos, lagos y tasas aduaneras.

84. HYG. (La. 116.12-15) = Th. 79.13-16: (...) alii per annos <quinos $>$, alii vero mancipibus ementibus, id est conducentibus in annos centenos, plures vero finito illo tempore iterum veneunt locanturque ita ut vectigalibus est consuetudo; (La. 116.21-23) = Th. 79.22-24: Mancipes autem, qui emerunt lege dicta ius vectigalis, ipsi per centurias locaverunt aut vendiderunt proximis quibusque possessoribus. 
verbos que hacen referencia a dos realidades muy diferentes como los son la venta y el alquiler, nos hace plantearnos, en primer lugar, la naturaleza de la concesión de estas tierras y, en segundo lugar, una explicación para el uso, posiblemente incorrecto, de tales términos.

Según el texto de Higino, la concesión del ager vectigalis podía hacerse, indistintamente, mediante una venta o un alquiler; sin embargo, si centramos nuestra atención en las fuentes jurídicas, la venta y alquiler son dos transaciones distintas y opuestas, y difícilmente pueden ser dos términos que traducen un mismo tipo de concesión de una parcela de tierra pública. Pero hay una serie de puntos que podrían explicar la confusión gromática: primero, el hecho de que entre los romanos los contratos de compraventa y de alquiler fuesen muy similares; segundo, que tal familiaridad la encontramos también entre los derechos y obligaciones del comprador y del arrendatario. Estas similitudes entre unos y otros confundían incluso hasta a los propios juristas, como es el caso de Gayo quien nos expone dos ejemplos al respecto: en el caso de que se entregasen gladiadores, se pagará un arrendamiento por aquellos que regresasen vivos de los juegos, pero con respecto a los caídos en la arena no se trata de un alquiler sino de una compraven$\mathrm{ta}^{85}$; el otro ejemplo es el de un joyero que fabrica un anillo para un particular, si lo hace con su propio oro se trata de una venta, pero si el particular es el que le da el oro se trata de un arrendamiento del joyero durante el tiempo que éste ha invertido en la realización de tal servicio ${ }^{86}$. La única diferencia que ve entre ambos tipos de contrato está marcada por el pretium y la merces $^{87}$.

En ambos casos estamos ante un contrato de tipo consensual que se constituía por el mutuo consentimiento de las partes, regido por la buena fe y en el que no se seguía ningún formalismo; así es como los expresa el jurista Paulo: La locatio-conductio por ser natural y de todas las gentes, no se contrae con palabras, sino por el consentimiento, como la compraventa" ${ }^{88}$. En la locatio-conductio las partes contratantes eran, por un lado, el locator, que era quien daba algo suyo, bienes muebles o inmuebles, en alquiler (locatio rei) a cambio del pago de una merces; y por otro lado, el conductor, que era quien se encargaba de arrendar las propiedades del primero. En la emptio-venditio se indicaban los dos elementos del contrato, emere para el comprador y vendere para el vendedor; una de las

85. GAIUS, Inst. III.146: (...) qui integri exierint, locationem et conductionem contractam videri, at eorum, qui occisi aut debilitati sunt, emptionem et venditionem esse (...).

86. GAIUS, Inst. III.147: Cassius ait materiae quidem emptionem venditionemque contrabi, operarum autem locationem et conductionem; sed plerisque placuit emptionem et venditionem contrabi. atqui si meum aurum ei dedero mercede pro opera constituta, convenit locationem conductionem contrabi.

87. GAIUS, Dig. 19.2.2.pr.: Locatio et conductio proxima est emptioni et venditioni isdemque iuris regulis constitit: nam ut emptio et venditio ita contrabitur, si de pretio convenerit, sic et locatio et conductio contrahi intellegitur, si de mercede convenerit.

88. PAUL. Dig. 19.2.1: Locatio et conductio cum naturalis sit et omnium gentium, non verbis, sed consensu contrabitur, sicut emptio et venditio. 
partes, el vendedor, transmitía la posesión de una cosa y garantizaba su pacífico goce mientras que la otra parte, el comprador, entregaba a cambio una suma de dinero, el pretium.

Otros vínculos que unen a estas dos operaciones son, por ejemplo, la existencia de la res locata fruenda: la locatio de un terreno considerada como la venta de los futuros frutos, es decir, que en lugar de alquilar un campo se vendía su cosecha ${ }^{89}$; así mismo era habitual vender o alquilar algo por un mayor pretium o merces de la que el objeto valía realmente, o a la inversa ${ }^{90}$; tanto en la venta como en el alquiler podían incumplirse los términos del contrato si éste aún no se había llevado a cabo porque una de las partes todavía no había cumplido con su obligación: dar el objeto en cuestión o bien el pago del precio o el alquiler ${ }^{91}$; por último, se podía pasar del arrendamiento de un objeto a su compra y así era posible que el comprador tomase en arrendamiento una parcela hasta que efectuase el pago de la misma ${ }^{92}$, si la compra no se conclía por no pagarse el precio estipulado por el vendedor, se originaba una actio locati, mediante la cual el arrendatario exigía las prestaciones del alquiler ${ }^{93}$.

La diferencia fundamental entre ambas formas de concesión, además de que con la compraventa se adquiría la propiedad del objeto, era la restitutio que sólo tenía lugar en los contratos de arrendamiento: una vez concluido el plazo y si éste no se renovaba, el conductor debía restituir los bienes, muebles o inmuebles, alquilados. En este sentido, el alquiler era una especie de "venta temporal" y sólo la restitutio, como apunta Gayo, marcaba la diferencia, como en el caso que hemos visto antes de los gladiadores: si hay devolución es un contrato de alquiler, si no se da la misma es un contrato de compraventa.

Es comprensible, por lo tanto, que dada la familiaridad entre una compraventa y un alquiler Higino emplee indistintamente los verbos vendere, emere, locare y conducere; este uso incorrecto es aún más comprensible si tenemos en cuenta que hasta entre los propios juristas romanos existían dudas a la hora de diferenciar uno de otro. Hay que añadir, además, que el tipo de alquiler que regía la concesión de la tierra pública, propiedad del Estado o de una comunidad, era in perpetuum, lo que significa que se prolongaba durante todo el tiempo que se efectuase el pago del vectigal y mientras asi ocurriese, el objeto, en este caso una parcela de tierra pública, no podía ser arrebatado ni al arrendatario ni a sus herederos $^{94}$. Esta perpetuidad y transferibilidad del ius in agro vectigale contribuye

89. CAT. Agr. 149.

90. PAUL. Dig. 19.2.22.3.

91. NERAT. Dig. 2.14.58.

92. PAUL. Dig. 19.2.20.

93. PAUL. Dig. 19.2.22.

94. SCAEV. Dig. 20.1.31.pr: Lex vectigali fundo dicta erat, $u$ t, si post certum temporis vectigal solutum non esset, is fundus ad dominum redeat (...). 
MARÍA JOSÉ CASTILLO PASCUAL

a que algunos, como Higino, identifiquen la locatio in perpetuum con una compraventa.

\section{MUNIFICENTIA}

En tres ocasiones nos encontramos este término en los tratados de agrimensura. Agennio Urbico al tratar de la controversia por el derecho sobre el territorio dice que uno de los derechos de las res publicae es defender su munificentia sobre estos lugares que aunque están alejados de su territorio caen dentro de su jurisdicción ${ }^{95}$. Sículo Flaco lo emplea al tratar sobre las condiciones civitatium y el origen etimológico de la palabra municipium: "algunos creen que se llaman municipios por las murallas; otros por la munificentia, porque eran ciudades sujetas a tasas" ${ }^{96}$. Y, por último, Higino Gromático al definir los fundi excepti como aquellas parcelas que "no deben ninguna munificentia a ninguna colonia" (aunque estuviesen ubicados dentro de su territorio) ${ }^{97}$.

La acepción habitual de munificentia es la de munificencia o generosidad, con ella se quiere indicar la realización de un acto de liberalidad por parte de un individuo hacia la comunidad en la que estaba integrado o en la que había nacido; era ser generoso (munificus). Sin embargo, aunque este el empleo normal de este término, en los textos gromáticos su significado es completamente distinto. Agennio Urbico e Higino Gromático emplea este término en el sentido de munificium que es todo lo que está obligado al pago de un derecho o de un canón. En el primero, los conflictos territoriales entre dos ciudades suponía la pérdida para la parte afectada de las tasas y munera que obtenía por los terrenos cuya usurpación habían originado el pleito; en el caso de Higino, por los fundi excep$t i$, ubicados en suelo del Pueblo romano, los propietarios no estaban obligados ni a pagar tasas ni a cumplir con los munera en la ciudad dentro de cuyos límites territoriales estaban ubicados. Sículo Flaco, por su parte, recoge la etimología tradicional de municipium en la que se refleja el principal de los deberes del municipes hacia su comunidad: cumplir con las cargas municipales (munera capere, muneris participes).

Los tratados de agrimensura son, en primer lugar, escritos técnicos en los que se describen los principios básicos del proceso de división del suelo para su posterior puesta en cultivo; pero también recogen algunas de las cuestiones jurídi-

95. AGENN. URB. (La. 84.19-22) =Th. 45.6-9: Inter res p. autem controversiae eius generis moventur, ut quaedam sui territorii iuris esse dicant, quamvis sint intra alienos fines, munificentiam quoque coloniae aut municipio ex bis locis / deberi defendant.

96. SIC. FL. (La. 135.18-19) = Th. 99.7-8: Municipia quidam putant a munitionibus dicta; alii a munificentia, eo quod munificae essent civitates. M. CLAVEL-LÉVEQUE et alii han traducido, erróneamente, la última frase como „elles étaient des citès généreuses“ (1993, p. 5).

97. HYG. GROM. La. (197.10-12) = Th. 160.11-13: excepti sunt fundi (..), nec ullam coloniae munificentiam deberent (...). 
cas inherentes a la ordenación romana del territorio, como son las categorías jurídicas del suelo y los pleitos que se originaban en relación con la propiedad y la delimitación de las parcelas. Desde este punto de vista, se justifica el empleo de un, no muy amplio, vocabulario jurídico que, en ocasiones, se aleja del sentido que él mismo tiene para un jurista; no debemos olvidar que los agrimensores, a pesar de su formación jurídica, eran técnicos de la groma y no maestros del derecho. Para ellos, las variadas connotaciones jurídicas de cada uno de los términos y su preciso significado pasan a un segundo plano. Por otra parte, la vaguedad y confusión que rodea a alguno de estos vocablos dificulta la comprensión del conjunto del texto; pero, en ocasiones, tampoco su significado es claro para los propios juristas, así es el caso de la confusión entre los verbos emere y locare que se emplean indistintamente. En la comprensión de los contenidos de esta familia de textos técnicos es fundamental no perder de vista las obras de los jurisconsultos romanos y otros textos de naturaleza jurídica, como las leyes de colonias y municipios, edictos, sentencias, etc. A los que continuamente hacen referencia los agrimensores para comprender la forma concreta en la que se organiza un determinado territorio. 
MARÍA JOSÉ CASTILLO PASCUAL

\title{
BIBLIOGRAFÍA
}

\author{
ALBERTARIO, E. 1914 \\ "Lis contestata e controversia mota": ZSS 35, pp. 305-319 \\ BERGER, A. 1953 \\ Encyclopedic Dictionary of Roman Law, Philadelphia. \\ BRUGI, B. 1897 \\ Le dottrine giuridiche degli agrimensori romani comparata a quelle del \\ Digesto , Verona-Padua.
}

CASAVOLA, F. 1959

"Controversia": NDI 4, Torino, p. 734-737.

CASTILLO, M.J.

"El nacimiento de una nueva familia de textos técnicos: la l iteratura gromática": Gerion (en prensa).

CASTILLO, M. J.

Espacio en orden. El modelo gromático-romano de ordenación del territorio, (en prensa) Logroño.

CLAVEL-LÉVÊQUE, M. 1993

Siculus Flaccus. Les conditions des terres, Napoli.

COLLINET, P. 1953

"La nature des querelae des origines à Justinien": SDHI 19, pp. 251-306.

DE RUGGIERO, E. 1895

s.v. "Abalienatio": Diz. Epigra. I, Roma, pp. 11-12.

DE RUGGIERO, E. 1895a

s.v. "Adsignatio": Diz. Epigra. I, Roma, pp. 102-115.

DE RUGGIERO, E. $1895 \mathrm{~b}$

s.v. “Arbiter": Diz. Epigra. I, Roma, p. 613-623.

DE RUGGIERO, E. 1910

s.v. "Controversia": Diz. Epigra. II.2, Spoleto, p. 1188.

DE VISSCHER, F. 1936

"Abalienatio": REL 14, pp. 130-134.

ELIACHEVITCH, B. 1942

La personalité juridique en droit privé romain, Paris.

HINRICHS, F.T. 1974

Die Geschichte der gromatischen Institutionen, Wiesbaden.

KASER, M. 1966

Das römische Zivilprozessrecht, München.

KUBITSCHEK, J. W. 1894

s.v. "Adsignatio": RE I.1, Stuttgart, cc. 426-428.

LE BOHEC, Y. 1989

La troisième légion Auguste, Paris.

LEIST, 1900.

s.v. "Controversia": Diz. Epigra. II.2, Spoleto, p. 1188.

WILKES, J. J. 1974

"Boundary Stones in Roman Dalmatia": Arbeoloski Vestnik 25, pp. 258-274. 